\title{
Effect of guar gum on glucose and water absorption from isolated loops of jejunum in conscious growing pigs
}

\author{
By ANNA L. RAINBIRD, A. G. LOW AND TERESA ZEBROWSKA† \\ National Institute for Research in Dairying, Shinfield, Reading, Berks RG2 9AT
}

(Received 3 February 1984 - Accepted 12 June 1984)

\begin{abstract}
1. Four pigs initially of $30 \mathrm{~kg}$ live weight were surgically prepared with two re-entrant cannulas in the jejunum $1.0 \mathrm{~m}$ apart which allowed an isolated loop to be formed through which solutions were perfused. ${ }^{51} \mathrm{Cr}$-EDTA was used as a marker for measuring net secretion or absorption.

2. A new Ringer solution was made, the ionic content of which resembled more closely that found in the jejunum of pigs given similar diets, than Krebs-Ringer solution.

3. The absorption of glucose and water from Krebs-Ringer and new Ringer solutions was compared.

4. The effect of guar gum on the absorption of glucose and water from solutions of glucose and maltose was studied.

5. There was a trend (not significant) for greater absorption of glucose and water from the new Ringer solution than from the Krebs-Ringer solution.

6. Guar gum significantly reduced the net absorption of glucose from glucose or maltose solutions from $\mathbf{7 4 \cdot 2}$ to $41.4 \%(P<0.001)$ and 71.1 to $35.0 \%(P<0.001)$ respectively.

7. Guar gum significantly reduced the net absorption of water from the glucose solution from $42 \cdot 7$ to $8.3 \%$ $(P<0.01)$ and from the maltose solution from 49.2 to $5.1 \%(P<0.001)$.

8. The lack of differences between the absorption of glucose from solutions of glucose or maltose suggested that maltase ( $E C$ 3.2.1.20) activity was not inhibited to the extent that this limited the rate of glucose absorption.
\end{abstract}

The beneficial effects of guar gum on glucose tolerance in normal (Jenkins et al. 1977) and diabetic (Jenkins et al. 1976) man are well established. The principal effect of adding guar gum to the diet is a decrease in postprandial hyperglycaemia. However, its mode of action remains unclear. Several hypotheses have been proposed to explain its action within the gut. These include a reduced rate of emptying of the stomach, altered motility in the stomach and small intestine, poorer mixing of digesta and enzymes in the gut lumen, slower hydrolysis of dietary components by brush-border enzymes in the small intestine and a reduction in the rate of absorption across the epithelial cell membrane (Low et al. 1982).

Johnson \& Gee (1981), using everted sacs prepared from rat jejunum, showed that guar gum significantly reduced the rate of glucose absorption in vitro. However, observations of the effect of guar gum in the intact anaesthetized rat are contradictory. Although no reduction in active sugar transport was seen by Förster \& Hoos (1977), Blackburn \& Johnson (1981) showed that pre-perfusion of a length of jejunum with a Ringer solution containing guar gum reduced subsequent glucose absorption.

The object of this experiment was to examine whether guar gum reduced the rate of absorption of glucose from isolated loops of jejunum in the conscious growing pig. The pig has previously been shown to be a suitable model of man for such studies (Leeds $e t$ al. 1980).

\footnotetext{
$\uparrow$ Present address: Institute of Animal Physiology and Nutrition, Polish Academy of Sciences, 05-110 Jablonna, near Warsaw, Poland.
} 


\section{EXPERIMENTAL METHODS}

Animals and surgery

Four male Large White $\times$ Landrace pigs of approximately $30 \mathrm{~kg}$ initial live weight were used. The animals were anaesthetized with a cyclopropane-nitrous oxide-oxygen mixture (20:40:40 by vol.) and two re-entrant cannulas were introduced into the jejunum following the general surgical procedures of Markowitz et al. (1954). Detailed aspects of the preparation were described by Horszczaruk et al. (1974). The first re-entrant cannula was approximately $2.0 \mathrm{~m}$ from the pylorus and the second re-entrant cannula $1.0 \mathrm{~m}$ distal to the first. This allowed an isolated loop of jejunum to be formed when required through which solutions could be perfused (Fig. 1). The cannulas were made from polyacetal (Kemetal ${ }^{\circledR}$; ICI Ltd, London) and had an internal diameter of $10 \mathrm{~mm}$.

The animals were allowed to recover in floor pens for 2 weeks following surgery before being transferred to metabolism cages for the experiment.

\section{Diet and feeding}

The composition of the diet used is shown in Table 1 . The pigs were weighed weekly and were fed at $42.5 \mathrm{~g} / \mathrm{kg}$ body-weight per d, in two equal meals at 09.00 and 21.00 hours. The diet was mixed with water $(1: 2 \cdot 5, \mathrm{w} / \mathrm{v})$ immediately before feeding.

\section{Determination of flow-rate for perfusions}

The flow-rate through a segment of jejunum in the pig in vivo can influence glucose absorption (Furuya \& Takahashi, 1975). Therefore during the first week of the experiment digesta were collected from the cannula nearest the pylorus for four consecutive days from 09.00 to $\mathbf{1 7 . 0 0}$ hours in order to measure their flow-rate. This was done to determine a suitable flow-rate for the subsequent perfusion trials. Each pig received the diet for $2 \mathrm{~d}$ with and $2 \mathrm{~d}$ without guar gum (Meyprogat $150^{\circledR}$; Meyhall Chemical (UK) Ltd, Wirral, Merseyside) at $60 \mathrm{~g} / \mathrm{kg}$ air-dry diet, in case the amounts of digesta were greatly altered by inclusion of guar gum. No significant differences in flow-rate were found between the diets.

Table 1. Composition of diet $(\mathrm{g} / \mathrm{kg}$ air-dry diet)

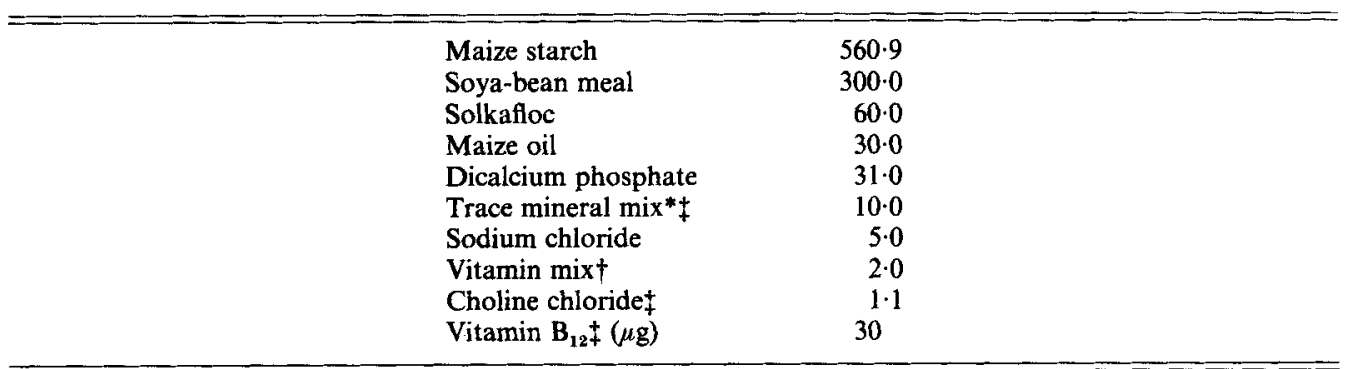

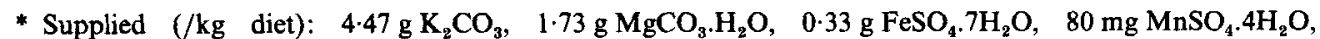
$0 \cdot 10 \mathrm{~g} \mathrm{ZnCO}_{3}, 8 \mathrm{mg} \mathrm{NaF}, 17.5 \mathrm{mg} \mathrm{CuSO}_{4} .5 \mathrm{H}_{2} \mathrm{O}, 6 \mathrm{mg} \mathrm{CoCl}_{2}$.

$\dagger$ Supplied (/kg diet): $12.5 \mathrm{mg}$ retinol, $0.6 \mathrm{mg}$ cholecalciferol, $3.25 \mathrm{mg}$ riboflavin, $2.0 \mathrm{mg}$ thiamin, $15.75 \mathrm{mg}$ nicotinic acid, $16.0 \mathrm{mg}$ pantothenic acid, $3.25 \mathrm{mg}$ pyridoxine, $4.0 \mathrm{mg}$ DL- $\alpha$-tocopheryl acetate, $5.0 \mathrm{mg}$ biotin, $1.0 \mathrm{mg}$ pteroylmonoglutamic acid, $195 \mathrm{mg} \psi$-inositol, $30.0 \mathrm{mg}$ ascorbic acid, $2.0 \mathrm{mg}$ menadione, $20.0 \mathrm{mg}$ $\rho$-aminobenzoic acid. All vitamins supplied by Roche Products Ltd, Dunstable, Beds, except $\psi$-inositol from SAS Chemicals Ltd, London and $\rho$-aminobenzoic acid from BDH Chemicals, Poole, Dorset.

$\ddagger$ BDH Chemicals, Poole, Dorset. 


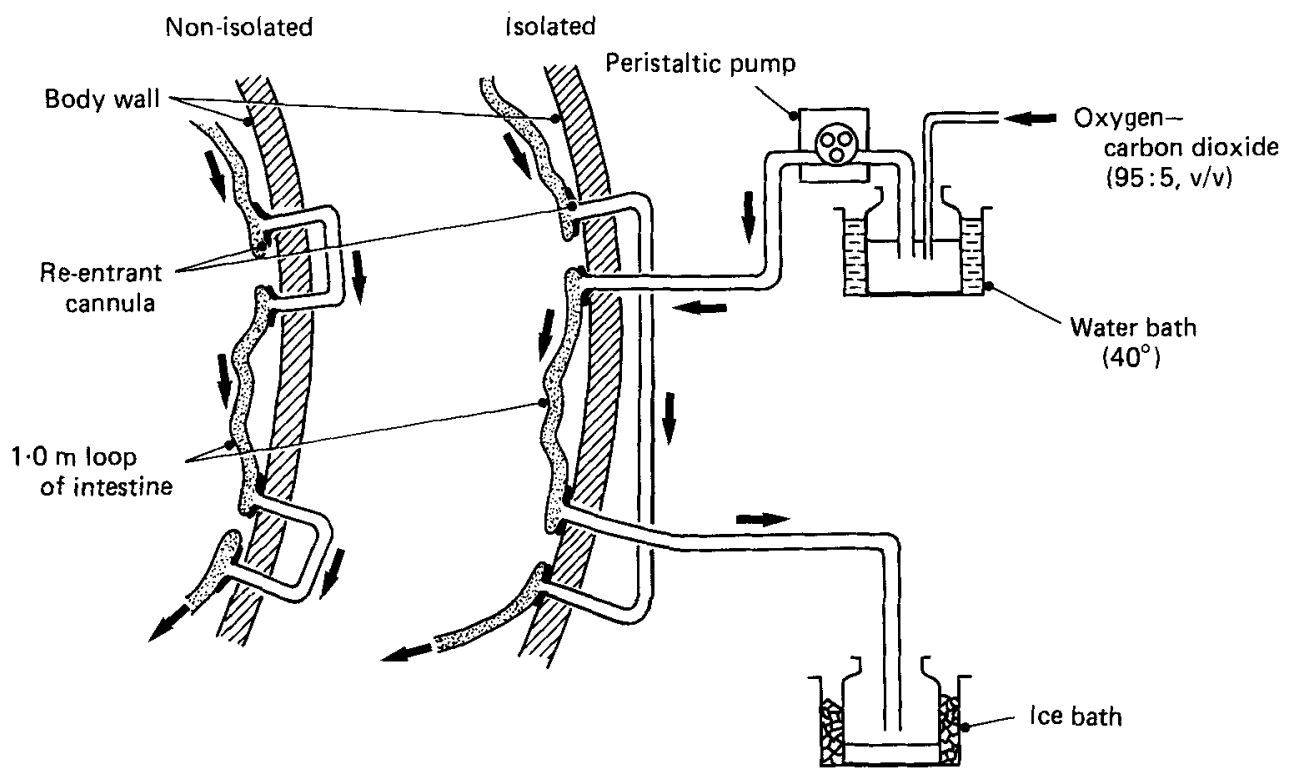

Fig. I. Intestinal loop (for details, see p. 490).

\section{Perfusion method}

During the perfusion studies in the following 5 weeks, the cannulas were connected before the morning feed so that an isolated loop of jejunum was formed (Fig. 1). The pigs were fed as usual, and digesta passed normally through the whole gut except for the $1.0 \mathrm{~m}$ loop in the jejunum. The perfusion solutions were kept at $40^{\circ}$ in a water-bath and continuously gassed with oxygen-carbon dioxide $(95: 5, \mathrm{v} / \mathrm{v})$. They were perfused through the loop using a peristaltic pump at a rate of $8 \mathrm{ml} / \mathrm{min}$ (the mean rate of digesta flow in this region determined in week 1 of the experiment) for $6.5 \mathrm{~h}$ daily starting at 08.30 hours. The loop was initially washed out using $50 \mathrm{ml}$ of the solution to be used that day before the $30 \mathrm{~min}$ pre-perfusion run. The loop was then perfused for $30 \mathrm{~min}$ to ensure that the loop had been satisfactorily washed free of digesta residues. The effluent collected during this period was discarded.

The solutions used during the following 6-h perfusion were marked with the non-absorbed complex of EDTA and ${ }^{51} \mathrm{Cr}\left({ }^{51} \mathrm{Cr}\right.$-EDTA) (Amersham International plc, Amersham, Bucks). During perfusions the cannula at the end of the loop was fitted with a $1.0 \mathrm{~m}$ length of PVC tubing (Layflat ${ }^{\circledR}, 50 \mathrm{~mm}$ wide; Transatlantic Plastics Ltd, Ventnor, Isle of Wight) into which the perfusate flowed. Every $2 \mathrm{~h}$ the perfusate, collected in a bottle surrounded by ice, was weighed and sampled. One sample was taken for immediate radioactive counting and another was frozen for subsequent analysis. In addition, a sample of the infusate was taken from each solution on every day and treated likewise. At the end of the perfusion period cannulas were reconnected so that normal flow of digesta through the loop was restored.

\section{Ringer solutions for perfusions}

Krebs-Ringer solution is generally regarded as the classical medium for studies on intestinal function. However, its ionic composition resembles that of blood serum and there are important differences between this and the ionic content of digesta collected from the 
Table 2. Composition of Krebs-Ringer and new Ringer solutions $(\mathrm{mm})$

\begin{tabular}{lcc}
\hline Salt & Krebs-Ringer & New Ringer \\
\hline Sodium chloride & 119.3 & 56.9 \\
Potassium chloride & 4.9 & 11.7 \\
Calcium chloride hexahydrate & 1.3 & 1.3 \\
Potassium dihydrogenphosphate & 1.2 & 1.2 \\
Magnesium sulphate heptahydrate & 1.2 & 1.2 \\
Sodium bicarbonate & 25.0 & 31.5 \\
\hline
\end{tabular}

All salts were of Analar grade supplied by BDH Chemicals Ltd, Poole, Dorset.

jejunum of growing pigs fed on similar semi-purified diets to those used in the present study (Partridge, 1978). Therefore, a new Ringer solution was made using the same salts as in Krebs-Ringer (Table 2) but in quantities which produced a solution resembling more closely the concentration of sodium and potassium in the jejunum. These cations were regarded as of particular importance because of their role in glucose absorption. In Krebs-Ringer, $\mathrm{Na}: \mathrm{K}$ is $14: 1$ but in the new Ringer solution this was reduced to $4 \cdot 5: 1$.

\section{Experimental scheme}

In week 2 of the trial, the absorption of glucose $(20 \mathrm{~g} / 1$; SAS Chemicals Ltd, London) and water from Krebs-Ringer and new Ringer solutions was compared. In addition, the possibility that glucose might have been secreted into the loops was examined using glucose-free solutions. Therefore four treatments were used: Krebs-Ringer, Krebs-Ringer with glucose, new Ringer, new Ringer with glucose. Each pig received each solution for one day in a Latin square design.

In the following 4 weeks, solutions of glucose or maltose $(20 \mathrm{~g} / \mathrm{l}$; SAS Chemicals Ltd, London), without or with guar gum $(6.7 \mathrm{~g} / 1)$ in new Ringer solution, were perfused through the loop; one solution/pig per week was used in a Latin square design. A concentration of $6.7 \mathrm{~g}$ guar gum/1 solution was used as this was the average calculated concentration in jejunal digesta in week 1 of this trial. The solutions containing guar gum had an apparent viscosity of $0.654 \mathrm{Ns} / \mathrm{m}^{2}(654 \mathrm{cP})$ at $40^{\circ}$ and a shear rate of $14 / \mathrm{s}$ as measured using a Haake Rotoviscometer (Model RV3; MSE Instruments Ltd, Manor Royal, Crawley, West Sussex). On day 1 of each week, the new Ringer solution alone was perfused through the loop to measure any glucose secretion into the loop. On days 2,3 and 4 the test solution was used.

\section{Analytical methods}

Samples of both the infusate and perfusate were counted for $2 \mathrm{~min}$ in an LKB-Wallac gamma sample counter, Model 80000 . The osmolarity of infusates was measured using an Advanced Laboratory Osmometer (Model 3L; Advanced Instruments, Needham Hill, Massachusetts, USA).

The samples containing maltose were hydrolysed in a steam bath for $75 \mathrm{~min}$ with hydrochloric acid added to give a final acid concentration of $0.5 \mathrm{M}$. These conditions were shown to give complete hydrolysis of maltose and recovery of glucose. These samples were then analysed with the remaining samples containing glucose using a glucose oxidase (EC 1.1.3.4)-peroxidase (EC 1.11.1.7) method (Boehringer Mannheim, Mannheim, W. Germany) on an automatic analyser (AutoAnalyzer AA1; Technicon Instruments Ltd, Basingstoke, Hants). 


\section{Use of ${ }^{51} \mathrm{Cr}$-EDTA and calculation of results}

The exact volumes of infusate and amounts of glucose and maltose which entered the isolated loop were calculated by relating the total amount of ${ }^{51} \mathrm{Cr}$-EDTA collected in the perfusate and concentration of ${ }^{51} \mathrm{Cr}$-EDTA in the infusate (necessary because of possible slight variations in the infusion rate, leakages, etc.). Comparisons of the amounts of ${ }^{51} \mathrm{Cr}$-EDTA which theoretically entered the loop (multiplying the amounts in the infusate bottle by the previously calibrated flow-rate of the peristaltic pump) and those actually collected showed a mean difference of $3 \%$, indicating that variations in the infusion rate and leakages were minimal. It was not possible to detect ${ }^{51} \mathrm{Cr}$-EDTA in the urine of the pigs and we thus conclude that it is a satisfactory non-absorbable marker. The presence of guar gum in the samples did not affect the counting of ${ }^{51} \mathrm{Cr}$. The amounts of glucose, maltose and water in the perfusate collected were calculated. The difference in the amount infused and collected was expressed as the net percentage absorbed.

\section{Statistical analysis of results}

The mean percentage net absorption of glucose and water over $6 \mathrm{~h}$ was calculated, and the effects of using Krebs-Ringer or new Ringer solutions on these processes were compared by analysis of variance. The effects of guar gum on glucose and water absorption were also assessed by analysis of variance.

The possibility that absorption may have altered over the 6-h perfusion period was investigated by analysis of variance of the results for the three successive 2 -h periods.

\section{RESULTS}

There were no problems with the surgical technique. The animals remained in good health for 2 months with no problems of leakage from the cannulas.

\section{Absorption of glucose and water from Krebs-Ringer and new Ringer solutions}

The percentage net absorption of glucose and water from Krebs-Ringer and new Ringer solutions is shown in Table 3. Although the mean net absorption of both glucose and water over the 6-h period was higher from the new Ringer solution, the differences were not statistically significant. There was no measurable secretion of glucose into the loops.

\section{Effect of guar gum on the absorption of glucose from glucose or maltose solutions} The effect of guar gum on the percentage net absorption of glucose and glucose derived from maltose is shown in Table 4.

Over the 6-h perfusion period, guar gum significantly reduced $(P<0.001)$ the net absorption of glucose from $74 \cdot 2$ to $41 \cdot 4 \%$ and of glucose derived from maltose from $71 \cdot 1$

Table 3. Percentage net absorption of glucose and water from Krebs-Ringer and new Ringer solutions during 6-h perfusion periods

(Mean values with standard errors of differences between means for four pigs/treatment)

\begin{tabular}{lcccc}
\hline & Krebs-Ringer & New Ringer & SED \\
\hline Glucose & 65.0 & 74.3 & NS & 7.54 \\
Water & 18.1 & 36.6 & NS & 13.89 \\
\hline
\end{tabular}

NS, not significant. 
Table 4. Effects of guar gum on percentage net absorption of glucose from solutions of glucose or maltose during 6-h perfusion periods (columns) and effects of time (rows)

(Mean values for each 2-h period with standard errors of differences (SED) between means for four pigs/treatment)

\begin{tabular}{|c|c|c|c|c|}
\hline \multirow[b]{2}{*}{ Solution } & \multicolumn{4}{|c|}{ Period of perfusion (h) } \\
\hline & 1 and 2 & 3 and 4 & 5 and 6 & $1-6$ \\
\hline Glucose & $81 \cdot 9^{\mathrm{a}}$ & $73 \cdot 0^{\mathrm{h}}$ & $67.7^{\mathrm{b}}$ & $74 \cdot 2$ \\
\hline Glucose + guar gum & $45 \cdot 5^{a}$ & $\begin{array}{c}42 \cdot 4^{\mathrm{a}} \\
* *\end{array}$ & $\begin{array}{c}39 \cdot 3^{a} \\
* *\end{array}$ & $\begin{array}{l}41 \cdot 4 \\
* * * *\end{array}$ \\
\hline \multirow{2}{*}{$\begin{array}{l}\text { Maltose } \\
\text { Maltose + guar gum }\end{array}$} & $73 \cdot 7^{\mathrm{a}}$ & $73 \cdot 0^{\mathrm{a}}$ & $66 \cdot 4^{a}$ & $71 \cdot 1$ \\
\hline & $\begin{array}{l}41 \cdot 0^{\mathrm{a}} \\
* * *\end{array}$ & $\begin{array}{l}36 \cdot 4^{\mathrm{a}} \\
* * * *\end{array}$ & $\underset{* * *}{27 \cdot 3^{b}}$ & $\begin{array}{l}35 \cdot 0 \\
* * * *\end{array}$ \\
\hline $\begin{array}{l}\text { Pooled SED for } \\
\text { means at the same } \\
\text { times (columns) }\end{array}$ & $4 \cdot 32$ & 5.47 & $6 \cdot 29$ & 3.65 \\
\hline \multicolumn{5}{|c|}{ Pooled SED for means of same solution (rows) 3.46} \\
\hline
\end{tabular}

Differences in absorption of glucose from glucose and maltose solutions were not significant $(P>0.05)$.

$\mathrm{a}, \mathrm{b}$ Within a horizontal row values with different superseript letters were significantly different $(P<0 \cdot 05)$.

** $P<0.01$, *** $P<0.001$.

to $35.0 \%$. Similar effects were seen when the results were analysed for each 2-h period. There were no significant differences between the absorption of glucose from solutions of glucose or maltose.

\section{Effect of guar gum on the absorption of water}

The effect of guar gum on the percentage net absorption of water is shown in Table 5. Guar gum significantly reduced the net absorption of water from solutions of both glucose (from 42.7 to $8.3 \% ; P<0.01$ ) and maltose (from 49.2 to $5.1 \% ; P<0.001$ ) during the 6-h perfusion period. Similar effects were seen when the results were analysed for each 2 -h period. There were no significant differences between the absorption of water from solutions of glucose or maltose.

Absorption of glucose from glucose or maltose solutions during the 6-h perfusion period The changes in the percentage net absorption of glucose from glucose or maltose solutions during the 6-h perfusion period are shown in Table 4 . When the results were examined closely, a trend for greater absorption of glucose in hours 1 and 2 than in hours 5 and 6 was observed. However, this was only significant for the solutions of glucose and maltose with guar gum $(P<0.01)$.

\section{Absorption of water during the 6-h perfusion period}

The changes in the percentage net absorption of water from solutions of glucose or maltose, without or with guar gum, during the 6-h perfusion period are shown in Table 5. There was always significantly greater $(P<0.01)$ absorption of water in hours 1 and 2 than in hours 5 and 6 from all four solutions.

\section{Osmolarity of infusates}

The osmolarity of the solutions infused is shown in Table 6 . The new Ringer solution had an osmolarity of $193 \mathrm{mosmol} / 1$, which was lower than that of the Krebs-Ringer solution ( $283 \mathrm{mosmol} / \mathrm{l}$ ). The osmolarity of both Ringer solutions was increased by the addition of 
Table 5. Effects of guar gum on percentage net absorption of water from glucose or maltose solutions during 6 -h perfusion periods (columns) and effects of time (rows)

(Mean values for each 2-h period with standard errors of differences between means for four pigs/treatment)

\begin{tabular}{|c|c|c|c|c|}
\hline \multirow[b]{2}{*}{ Solution } & \multicolumn{4}{|c|}{ Period of perfusion (h) } \\
\hline & 1 and 2 & 3 and 4 & 5 and 6 & $1-6$ \\
\hline Glucose & $52 \cdot 4^{\mathrm{a}}$ & $42 \cdot 1^{D}$ & $33 \cdot 5^{\mathrm{c}}$ & $42 \cdot 7$ \\
\hline \multirow[t]{2}{*}{ Glucose + guar gum } & $19 \cdot 8^{\mathrm{a}}$ & $3 \cdot 1^{b}$ & $1 \cdot 3^{\mathrm{b}}$ & $8 \cdot 3$ \\
\hline & $* *$ & $* * *$ & $* *$ & $* *$ \\
\hline Maltose & $55 \cdot 0^{\mathrm{a}}$ & $51 \cdot 0^{\mathrm{a}}$ & $41 \cdot 7^{b}$ & $49 \cdot 2$ \\
\hline \multirow{2}{*}{ Maltose + guar gum } & $20 \cdot 7^{\mathrm{a}}$ & $-1 \cdot 6^{\mathrm{b}}$ & $-3 \cdot 9^{b}$ & $5 \cdot 1$ \\
\hline & $* *$ & $* * *$ & ** & \\
\hline \multicolumn{5}{|l|}{$\begin{array}{l}\text { means at the same } \\
\text { times (columns) }\end{array}$} \\
\hline \multicolumn{5}{|c|}{ Pooled SED for means of same solution (rows) $3 \cdot 10$} \\
\hline
\end{tabular}

Differences in absorption of water from glucose and maltose solutions were not significant $(P>0.05)$.

$\mathbf{a}, \mathbf{b}, \mathbf{c}$ Within a horizontal row values with different superscript letters were significantly different $(P<0.05)$.

${ }^{* *} P<0.01,{ }^{* * *} P>0.001$.

glucose or maltose. Addition of guar gum to the infusates had only a small additional effect on osmolarity. The mean osmolarity of digesta collected from the cannula nearest the stomach was $391 \mathrm{mosmol} / \mathrm{l}$ when the control diet was fed and $426 \mathrm{mosmol} / \mathrm{l}$ when guar gum was added to the diet. Pig blood-plasma was found to have an osmolarity of $278 \mathrm{mosmol} / \mathrm{l}$.

\section{Amounts of glucose or maltose absorbed}

The net weights $(\mathrm{g} / \mathrm{h}$ per $\mathrm{m}$ small intestine) of glucose absorbed from glucose or maltose solutions can be calculated by multiplying the infusion rate of glucose or maltose of $9.6 \mathrm{~g} / \mathrm{h}$ $(8 \mathrm{ml} / \mathrm{min} \times 20 \mathrm{~g} / \mathrm{l})$ by the percentage net absorption. For example, from Table 4 , the amounts of glucose absorbed for the four time-periods were: $7 \cdot 86,7 \cdot 01,6 \cdot 50$ and $7 \cdot 12 \mathrm{~g} / \mathrm{h}$ per $\mathrm{m}$.

Table 6. Osmolarity of infusate solutions

\begin{tabular}{lc}
\hline Infusate & $\begin{array}{c}\text { Osmolarity } \\
\text { (mosmol } / 1)\end{array}$ \\
\hline Krebs-Ringer & 283 \\
New Ringer & 193 \\
Krebs - Ringer +20 g glucose $/ 1$ & 385 \\
New Ringer $+20 \mathrm{~g}$ glucose $/ 1$ & 294 \\
New Ringer $+20 \mathrm{~g}$ maltose $/ 1$ & 244 \\
New Ringer $+20 \mathrm{~g}$ glucose $+6.7 \mathrm{~g}$ guar gum $/ 1$ & 310 \\
New Ringer $+20 \mathrm{~g}$ maltose $+6.7 \mathrm{~g}$ guar gum $/ 1$ & 265 \\
\hline
\end{tabular}




\section{DISCUSSION}

\section{General}

Perfusion of an isolated loop of jejunum in the pig in vivo was found to be a practicable method for studying glucose and water absorption over a 6-week period.

Re-entrant cannulation involves transection of the intestine between the cannulas, and thus there is an interruption of the continuity of the muscle layers and the nervous system. Motility is thought to be normal proximal to the re-entrant cannula in pigs but it can be disturbed distally (Laplace, 1980). As motility in the jejunal loops was not recorded in our experiment the influence of possible abnormal motility on the results is not known.

It should be remembered that, following a meal, digesta does not move continuously and at a constant speed within the gut, while the perfusions were made at a uniform rate. The extent to which this difference might have influenced the results is impossible to estimate.

As the osmolarities of the solutions used were very similar, observed differences in absorption cannot be explained on this basis.

\section{Krebs-Ringer v. new Ringer solution}

No significant differences in the absorption of glucose and water from the Krebs-Ringer and new Ringer solutions were seen although the trend was for greater absorption from the new Ringer solution (Table 3). This trend might have assumed significance had more than one measurement been made per animal, or more animals studied. Nevertheless, it seemed sensible to choose a solution with a mineral content which resembled that of the digesta flowing through the jejunum. Digesta would be the ideal material for perfusion through the loop and this was attempted at the end of the experiment; however, many drawbacks were found with this approach. As a result of this experience, it is suggested that a solution or suspension of protein, fats, carbohydrates and minerals at concentrations in which they are found in the region of the gut to be perfused might be the best physiological compromise available for future studies.

\section{Glucose and water absorption}

The results showing that guar gum halved the rate of absorption of glucose from both glucose and maltose solutions from the jejunum of growing pigs during a 6 -h perfusion period in vivo (Table 4), are in general agreement with previous work in rats in vitro by Elsenhans et al. $(1980,1981)$ and Johnson \& Gee (1981) and in vivo by Blackburn \& Johnson (1981).

The lack of differences between the absorption of glucose and of glucose derived from maltose in the present study (Table 4) suggests either that guar gum did not inhibit maltase (EC 3.2.1.20) activity, or that there was sufficient excess maltase activity to overcome any inhibition by guar gum. This is in agreement with the observations of Elsenhans et al. (1981) who showed that maltase activity in jejunal mucosal homogenates was unaltered by guar gum.

There are several possible explanations for the marked reduction in the absorption of glucose observed when guar gum was added to the glucose or maltose solutions. These include a slower rate of diffusion of glucose or maltose from the gut lumen towards the epithelial surface (Khan et al. 1979; Taylor et al. 1980) and an increase in the thickness of the mucosal unstirred layer (Johnson \& Gee, 1981). It has also been suggested that guar gum might result in distension of a perfused intestinal loop, leading to a wider separation of villi and a greater surface area for inhibitory effects on absorption to occur (Blackburn et al. 1984). Table 5 shows that the amount of water in the intestinal loop was increased by the presence of guar gum, but since the loop was open it is difficult to know whether 
it was distended at all and, if so, whether this was sufficient for these suggested effects to occur.

A slower diffusion of glucose or maltose from the gut lumen to the epithelial cell membranes because of the increased viscosity caused by guar gum may explain the observed reduction in the rate of absorption of glucose from glucose or maltose solutions. Such an interpretation is consistent with studies made in vitro in which the rate of diffusion of glucose from a dialysis bag (representing the small intestine) was significantly reduced by guar gum (10 and $33 \mathrm{~g} / 1)$ (Khan et al. 1979; Taylor et al. 1980). It has recently been suggested (Blackburn et al. 1984) that convective solute movement might be another factor which is reduced by guar gum within the intestinal lumen and that the importance of diffusion could be limited to movement in the unstirred region adjacent to the epithelium.

Since absorption was more markedly reduced by guar gum in hours 5 and 6 than in hours 1 and 2 , it is also possible that the apparent thickness of the mucosal unstirred layer was gradually increasing throughout the perfusion period. Johnson \& Gee (1981) found that the apparent thickness of the mucosal unstirred layer increased by $48 \%$ in rat jejunal sacs in vitro incubated for $15 \mathrm{~min}$ in a guar gum solution. This was confirmed by Elsenhans et al. (1981) during experiments on the effect of guar gum on the kinetics of glucose transport in vitro.

It seems likely that a combination of factors is responsible for the observed reduction in glucose absorption when guar gum was added to solutions of glucose or maltose. In the studies of Johnson \& Gee (1981), addition of guar gum to the incubation medium caused a $74 \%$ reduction in glucose transport whereas pre-incubation of jejunal sacs with guar gum only reduced subsequent glucose absorption by $59 \%$; the authors concluded that more than one mechanism was operating.

The luminal contents of the small intestine are known to be more viscous after consumption of diets containing guar gum compared with controls (Blackburn \& Johnson, 1981; A. L. Rainbird, unpublished results). This may be responsible for reduction in the rate of glucose absorption from the small intestine which may in turn explain the reduction in post-prandial hyperglycaemia seen after addition of guar gum to a meal.

A very marked reduction in water absorption from solutions of both glucose and maltose was observed when guar gum was added to the infusate (Table 5). This may be related to the water-holding capacity of guar gum. Using sacs of dialysis tubing immersed in simulated gut contents in vitro, Stephen \& Cummings (1979) found that after a 24-h incubation period, $1 \mathrm{~g}$ guar gum could hold $21.4 \mathrm{~g}$ water. Using this value, the water-holding capacity of the guar gum used in the present study was $140 \mathrm{ml} / 1$ infused. The reduction in net water absorption as a result of the presence of guar gum was $344 \mathrm{ml} / 1$ (Table 5). Thus water-holding capacity may have been one of the factors responsible for the reduced net water absorption from solutions containing guar gum.

Over the 6-h perfusion period a trend for greater absorption of glucose from solutions of glucose or maltose in hours 1 and 2 than in hours 5 and 6 was seen, although differences were only significant for solutions of glucose and maltose with guar gum (Table 4). Water absorption from all solutions was least in hours 5 and 6 and highest in hours 1 and 2 (Table 5). This suggests that an adaptation of the gut to the solutions may have occurred during the 6-h perfusion period. In addition, the influence of feeding cannot be discounted: Sarr et al. (1981) found net water and glucose absorption was greater shortly after feeding than during fasting; this appeared to be due in part to hormonal influences. Motility may also have played a role in this respect: post-prandial patterns of small intestinal motility are known to change with time after feeding (Bueno \& Ruckebusch, 1976). In the case of solutions containing guar gum, it is also plausible that the small intestine was gradually being coated with the viscous solution thus reducing the rate of absorption, the effect increasing during the perfusion period. 
The authors would like to thank Dr H. L. Buttle for surgery, Dr I. E. Sambrook, Messrs A. R. Jones, J. R. Abbey and J. A. King for care of the experimental animals, Mr H. A. Smith for technical assistance and Mrs R. J. Fulford for advice on the design of the experiments and on the statistical analysis of the results. A.L.R. acknowledges receipt of an Agricultural and Food Research Council research studentship. T.Z. was supported by a grant from the Underwood Fund of the Agricultural and Food Research Council. They thank Mr R. M. W. Hopkins of Meyhall Chemical (UK) Ltd for the gift of guar gum.

\section{REFERENCES}

Blackburn, N. A. \& Johnson, I. M. (1981). British Journal of Nutrition 46, 239-246.

Blackburn, N. A., Redfern, H., Jarjis, A. M., Holgate, A. M., Hanning, I., Scarpello, J. H. B., Johnson, I. T. \& Read, N. W. (1984). Clinical Science 66, 329-336.

Bueno, L. \& Ruckebusch, M. (1976). American Journal of Physiology 230, 1538-1544.

Elsenhans, B., Süfke, U., Blume, R. \& Caspary, W. F. (1980). Clinical Science 59, 373-380.

Elsenhans, B., Süfke, U., Blume, R. \& Caspary, W. F. (1981). Digestion 21, 98-103.

Förster, H. \& Hoos, I. (1977). Zeitschrift für Ernährungswissenschaft 16, 140-149.

Furuya, S. \& Takahashi, S. (1975). British Journal of Nutrition 34, 267-277.

Horszczaruk, F., Buraczewska, L. \& Buraczewski, S. (1974). Roczniki nauk Rolniczych 95B4, 69-77.

Jenkins, D. J. A., Leeds, A. R., Gassull, M. A., Cochet, B. \& Alberti, K. G. M. M. (1977). Annals of Internal Medicine 86, 20-23.

Jenkins, D. J. A., Leeds, A. R., Gassull, M. A., Wolever, T. M. S., Goff, D. V., Alberti, K. G. M. M. \& Hockaday, T. D. R. (1976). Lancet ii, 172-174.

Johnson, I. M. \& Gee, J. M. (1981). Gut 22, 398-403.

Khan, P., MacRae, R. \& Robinson, R. K. (1979). Laboratory Practice 28, 260.

Laplace, J. -P. (1980). In Current Concepts of Digestion and Absorption in Pigs, pp. 2447 [A. G. Low and I. G. Partridge, editors]. Reading: National Institute for Research in Dairying.

Leeds, A. R., Kang, S. S., Low, A. G. \& Sambrook, I. E. (1980). Proceedings of the Nutrition Society 39, 44A.

Low, A. G., Rainbird, A. L. \& Gurr, M. I. (1982). Journal of Plant Foods 4, 29-32.

Markowitz, J., Archibald, J. \& Downie, H. G. (1954). Experimental Surgery, 3rd ed. London: Baillière Tindall \& Cox.

Partridge, I. G. (1978), British Journal of Nutrition 39, 527-537.

Sarr, M. G., Kelly, K. A. \& Phillips, S. F. (1981). Digestive Diseases and Sciences 26, 961-965.

Stephen, A. M. \& Cummings, J. H. (1979). Gut 20, 722-729.

Taylor, R. H., Wolever, T. M. S., Jenkins, D. J. A., Ghafari, H. \& Jenkins, M. J. A. (1980). Gut 21, A452. 